\title{
A Study on Modeling the Price Trend of Black Pepper in Malaysia
}

\author{
Nur Aifiah Binti Ibrahim \\ No. 4, Jalan Puchong 2, Taman Perling, \\ 81200 Johor Bahru, Johor Darul Takzim, \\ Malaysia. \\ Tel: 014- 2725013 E-mail: nuraifiahibrahim90@ gmail.com

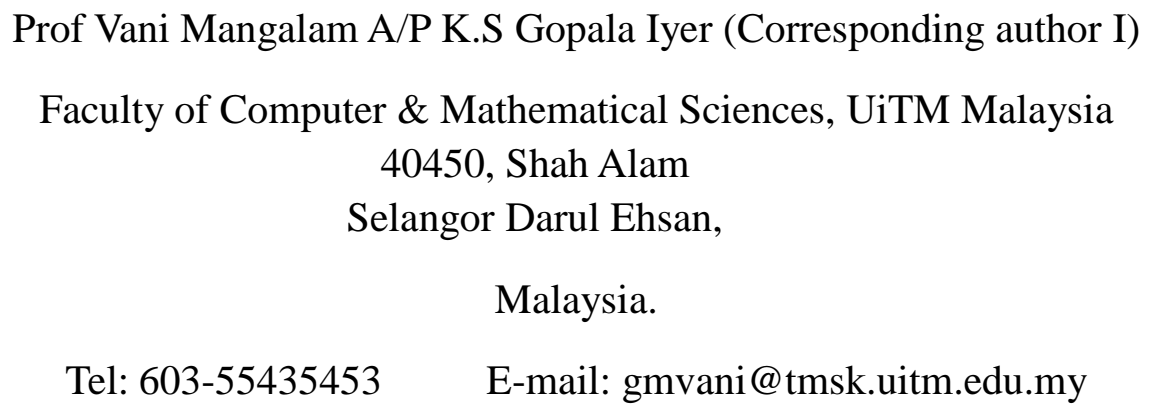

Prof Hamdan Maad (Corresponding author II)

Faculty of Computer \& Mathematical Sciences, UiTM Malaysia

40450, Shah Alam

Selangor Darul Ehsan,

Malaysia.

Tel: 603-55435420Ｅ-mail: hamdan@tmsk.uitm.edu.my

Received: August 7, 2016 Accepted: August 22, 2016 Published: October 15, 2016

doi:10.5296/jas.v4i4.10162 URL: http://dx.doi.org/10.5296/jas.v4i4.10162

\begin{abstract}
The pepper industry represents a significant economic sector in Malaysia. Despite the importance of the pepper industry to the Malaysian economy, the review of the literature
\end{abstract}


indicates that the industry has not attracted much research emphasis. More specifically, the literature indicates that limited studies have attempted to investigate the factors that influence the price of black pepper in Malaysia. Furthermore, the factors that influence the pricing of black pepper can be identified by selecting the most suitable multivariate model. Hence, Multiple Linear Regression and VAR model are conducted and compared for determining on which of the factors are significant for the pricing values of black pepper. The secondary data on the economic variables of black pepper is obtained from the Malaysian Pepper Board which is located in Kuching, Sarawak. The analysis of the data can be divided into estimation and evaluation part. In the estimation part, both types of model are developed and Cochrane Orcutt procedure is undertaken to diagnose the autocorrelation problem in Multiple Linear Regression model. In terms of multivariate approach it is found that VAR model is more reliable than Multiple Linear Regression since it has smaller readings in most of the criterions such as MSE and RMSE. Therefore, it can be identified that lagged one of economic variables such as amount of production, amount of export and pricing of black pepper are significant factors that affect the annual pricing of the agricultural product.

Keywords: Multiple Linear Regression, VAR, MSE, RMSE, Cochrane- Orcutt

\section{Introduction}

The factors that might affect the pricing of black pepper would be amount of production, total amount of consumption and amount of export. In order to identify the significant factors, Multiple Linear Regression and Vector Autoregressive models may be applicable for this research. Ravindran (2004) had stated that as the amount of production increases, the pricing of pepper will increase as well. Thus, Halberg (2006) had found that if the amount of production increases, the pricing values for major crop plantations will also increase. In this case, Alice \& Peter (2007) had listed down the major crop commodities around the world as coffee, tea, pepper and natural rubber. Besides that, Csaki (2002) had discovered that the consumption of food and agricultural products may influenced the price variations. Even Redclift (2002) had mentioned amount of consumption in the food market may be related to the price movements of agricultural products. Then, Ravindran (2004) had also found that the price of pepper increases as the amount of production and export increases or vise versa. Narne \& Lakdawala (2008) had stated that the exports of pepper are lesser than domestic consumptions but it does the pricing globally. Other than that, Paul Ebeling (April 22, 2014) had reported in a newspaper article titled "Vietnam's Pepper Exports Expected To Earn US\$1-B In 2014", Vietnam had contributed 50\% of pepper export worldwide and it was also found that it has a great influence on the pricing of different spices.

\subsection{Multiple Linear Regression}

Abay (2010) had conducted Multiple Linear Regression analysis to estimate quantity of red pepper that were supplied to the market in Bure Woreda, Ethiopia. The quantity of red pepper could be dependent on amount of yield, land size, current market price, previous year on market prices and distance to market. From a survey among $85.3 \%$ of farmers were sampled in the year 2008/2009 production of red pepper that was supplied to the market. As a result, total yield, land size, credit services, current year market price, previous year on market prices and number of years of experience in red pepper production are significant factors that 
might affect the quantity of supply for red pepper. Udgebe et al. (2012) had applied Multiple Linear Regression analysis to relate the transportation cost and storage facilities with the sales volume and pricing of pepper. It is found that transportation cost might have a significant influence on the pricing of pepper in Lagos markets, Nigeria. Therefore, the peppers were sold at lower prices to avoid more losses due to spoilage.

\subsection{Vector Autoregressive}

Lau et al. (2008) had studied the causality effect among white and black pepper in different areas of Sarawak by using Vector Autoregressive (VAR) model. It is discovered that there were interdependencies among the monthly pricing of both types of pepper dated from January 1990 until June 2005 across different markets in Sarawak including Kuching, Sri Aman, Bintangor, Sarikei, Sibu and Batu Niah. Kaspersen \& Føyn (2010) had applied VAR model to determine the impact of world prices of sorghum and coffee on the local pricing for both products in Uganda market. The data for this study is obtained from FoodNet market information project and International Coffee Organisation. However, the data on weekly prices of sorghum is from June 2000 until September 2006 where as the monthly pricing of coffee was dated from January 1986 until April 2006. It can be summarised that the food prices in world markets is indirectly related to the local pricing in Uganda market. Thus, there is a direct effect of world market prices of coffee on the Uganda market. Luo (2011) had formulated VAR model to relate the external factors that might affect the price fluctuations in the domestic agricultural products of China starting from the month of January 2002 until June 2010. Based on the findings, the transmission of price fluctuation of international agricultural products, the contribution degree of petroleum price and international speculation capital rank the second and the third are identified as significant factors that influence pricing of domestic agricultural products in China.

\section{Methodology}

The main assumption for both multivariate methods is to determine whether the economic variables of black pepper are stationary or not by applying Augmented Dickey Fuller test.

\subsection{Multiple Linear Regression}

The model is estimated by using Ordinary Least Squares method. The parameters of $b_{0}$ and $b_{1}$ are expressed as shown below.

$$
\begin{gathered}
b_{0}=\bar{Y}-b_{1} \bar{X} \\
b_{1}=\frac{\sum\left(X_{i}-\bar{X}\right)\left(Y_{i}-\bar{Y}\right)}{\sum\left(X_{i}-\bar{X}\right)^{2}}
\end{gathered}
$$

The general multiple linear regression can be formulated as follows:

$$
Y=\beta_{0}+\beta_{1} X_{1}+\beta_{2} X_{2}+\beta_{3} X_{3}+\varepsilon
$$


Where:

$Y=$ Pricing value of black pepper (RM in thousands/Tonne)

$X_{1}=$ Amount of production of black pepper (Tonnes)

$X_{2}=$ Total amount of consumption of black pepper (Tonnes)

$X_{3}=$ Amount of Export (Tonnes)

$\varepsilon \sim N\left(0, \sigma^{2}\right)$

As mentioned by Wooldridge (2012), multiple linear regression that is applied for time series data can have autocorrelation problems among the error terms. Therefore, the problem can be diagnosed by using Cochrane- Orcutt procedure for transforming the response and predictor variables of the model (Samprit \& Hadi, 2013). Hence, Kutner et al. (2008) had listed down several steps to conduct this procedure as follows:

1. The estimation of $\rho$. The autoregressive error process can be obtained from the following equation.

$$
\varepsilon_{t}=\rho \varepsilon_{t-1}+u_{t}
$$

Where

$\varepsilon_{t}$ is the error term.

$\varepsilon_{t-1}$ represents the error terms at lag 1 that is the predictor variable of the model.

$\rho$ is known as the autoregressive error process which also referred to as the slope of the line through the origin.

$u_{t}$ represents the mean of the error term for the regression model.

Therefore, $\rho$ which is denoted as $r$ can be computed as shown below.

$$
r=\frac{\sum_{t=2}^{n} e_{t-1} e_{t}}{\sum_{t=2}^{n} e^{2}{ }_{t-1}}
$$

2. The variables are transformed which can be represented as $Y^{\prime} t$ and $X^{\prime} t$. Both variables can be formulated as follows: 


$$
Y_{t}^{\prime}=Y_{t}-r Y_{t-1}
$$

Where

$Y^{\prime}{ }_{t}$ resembles the transformed response variable, the pricing value of black pepper.

$Y_{t-1}$ is the lagged one for pricing value black pepper.

$$
X_{t}^{\prime}=X_{t}-r X_{t-1}
$$

Where

$X_{t}^{\prime} \quad$ represents the transformed variable for significant predictor variables on the pricing value of black pepper.

$X_{t-1}$ is the lagged one for the significant independent variables that influence the pricing of black pepper.

3. Durbin Watson test is carried out again for this regression model with the transformed variables. If the error terms are uncorrelated then, the procedure does not need to be iterated.

\subsection{Vector Autoregressive Model}

Stock \& Watson (2001) had also added that VAR models can be in either reduced, recursive or structural form. In this research, the focus is on the reduced form of VAR model that relate each one of the economic variables of black pepper in various equations which are also dependent on their past values. Hyndman and Athanasopoulos (2012) had proposed asymptotic Portmanteau test for further confirmation on the lag order selection for the Vector Autoregressive model. The main reason for conducting this test is to ensure there is no serial correlation among the residuals. In terms of the order of differencing or known as the lag order, Luetkepohl (2011) had stated that the variables may appear in first differences, $I(1)$ but not be cointegrated with each other meaning that the non stationary variables may not be related with each other at different lag lengths. Therefore, it is already sufficient to conduct the reduced form of VAR model to examine the behavioural relations in the economy of black pepper. The general formula for VAR model can be equated as shown below.

$$
y_{t}=u_{t}+x_{t}
$$

The equations consists of deterministic and stochastic components which are represented as $u_{t}$ and $x_{t}$. The deterministic component can be in different conditions. The first one is the linear trend that can be included as the deterministic component in the model as follows: 


$$
u_{t}=u_{0}+u_{1 t}
$$

It can be also be assumed as non- constant, $u_{t=0}$ and also as a constant, $u_{t}=u_{0}$ which is for the simplicity of the VAR model. In terms of forecasting, this component plays an important role in predicting the values for each of the economic variables of black pepper for this research. The other component is the stochastic in which the order of integration and cointegration relations are determined by the computation of $x_{t}$. The $y_{t}$ is the vector of observed variables which is determined by both components in the model. In this study, the variables such as pricing value, amount of production, total consumption and amount of export of black pepper are the vector of observed variables and they are linearly related with each other by inserting the main components of deterministic and stochastic. However, Luetkepohl (2011) emphasised on the stochastic part of the variables in terms of econometric analysis because it describes the behavioural relations among them. It is optional to either include or not the deterministic part of the model. The comparison among models is evaluated by the use of specified criterions. Alias (2011) had suggested several steps for evaluation phase. The steps are as follows:

Step 1: The data is divided into estimation part and evaluation part for forecasting performance.

Step 2: For estimation part, $75 \%$ of data will be included to estimate the model.

Step 3: The other $25 \%$ will be taken to the evaluation part where each of the models will be compared according to the specified criterions.

As mentioned before, the models are compared based on criterions such as mean squared error (MSE), root mean squared error (RMSE) and also mean absolute percentage error (MAPE). The following would be the formulations for each of them.

Mean Squared Error, MSE

$$
M S E=\frac{\sum_{t}^{N} e_{t+1}^{2}}{n}
$$

Root Mean Squared Error, RMSE

$$
R M S E=\sqrt{\frac{\sum_{t}^{n} e_{t+1}^{2}}{n}}
$$

Mean Absolute Percentage Error 


$$
\sum_{t=1}^{n} \frac{\left|\left(e_{t} / y_{t}\right) \times 100\right|}{n}
$$

\section{Results and Findings}

\subsection{Multiple Linear Regression}

By applying the cross correlation function as proposed by Cowpertwait \& Metcalfe (2009), the relationships among economic variables such as Production, Consumption, Export and Pricing at different time lags can be plotted. Furthermore, stepwise regression model is used and it is found that the model has autocorrelation problem by conducting the Durbin Watson test. Due to the presence of autocorrelation problem in the regression model, CochraneOrcutt procedure will be applied as proposed by Samprit \& Hadi (2013). Hence, the response and predictor variables would be transformed into new variables by computing this procedure. Therefore, the regression model can be equated as follows:

$$
\hat{y}_{t}=1147+0.8733 y_{(t-1)}^{\prime}-0.00006 y^{\prime 2}(t-2)
$$

Where

$\hat{y}_{t}$ is the transformed pricing value of black pepper.

$\hat{y}_{(t-)}$ is the transformed variable for the Pricing at lag 1.

$y^{\prime 2}{ }_{(t-2)}$ represents the transformed variable for quadratic term of Pricing at lag 2.

Based on the F statistic and the p-value (0.0007), the model is found to be significant. It was also found that the predictor variables, Pricing at lag 1 and quadratic term for Pricing at lag 2 are both significant since the p-values $(0.0002 \& 0.0438)$ are lower than the critical value of 0.05. However, the computation on the Multiple R-Square with the value of 0.5786 for this model seems to be lower than the previous regression proving that the $57.86 \%$ of variations in the pricing value of black pepper can be explained by the Pricing at lag 1 by quadratic term for Pricing at lag 2. The other $42.14 \%$ can be explained by other factors.

By conducting Jarque Bera test, the residuals are proven to be normally distributed since the p-value (0.5581) is not significant. Based on Figure 1, it can be seen that there are a few extreme residuals values present in the plot. As mentioned by Cramb (2007), the Asian economic crisis in 1997 had caused the over fluctuations of the pricing on black pepper. By referring to Figure 2 and 3, the residuals are scattered and not forming systematic pattern which shows that there is no presence of heteroscedasticity. Furthermore, Breuch- Pagan test had shown that the error terms have a constant variance and there is no serial autocorrelation at first order which is statistically proven by applying the Durbin Watson test. Hence, it does not violate one of the assumptions pertaining to the error term. 


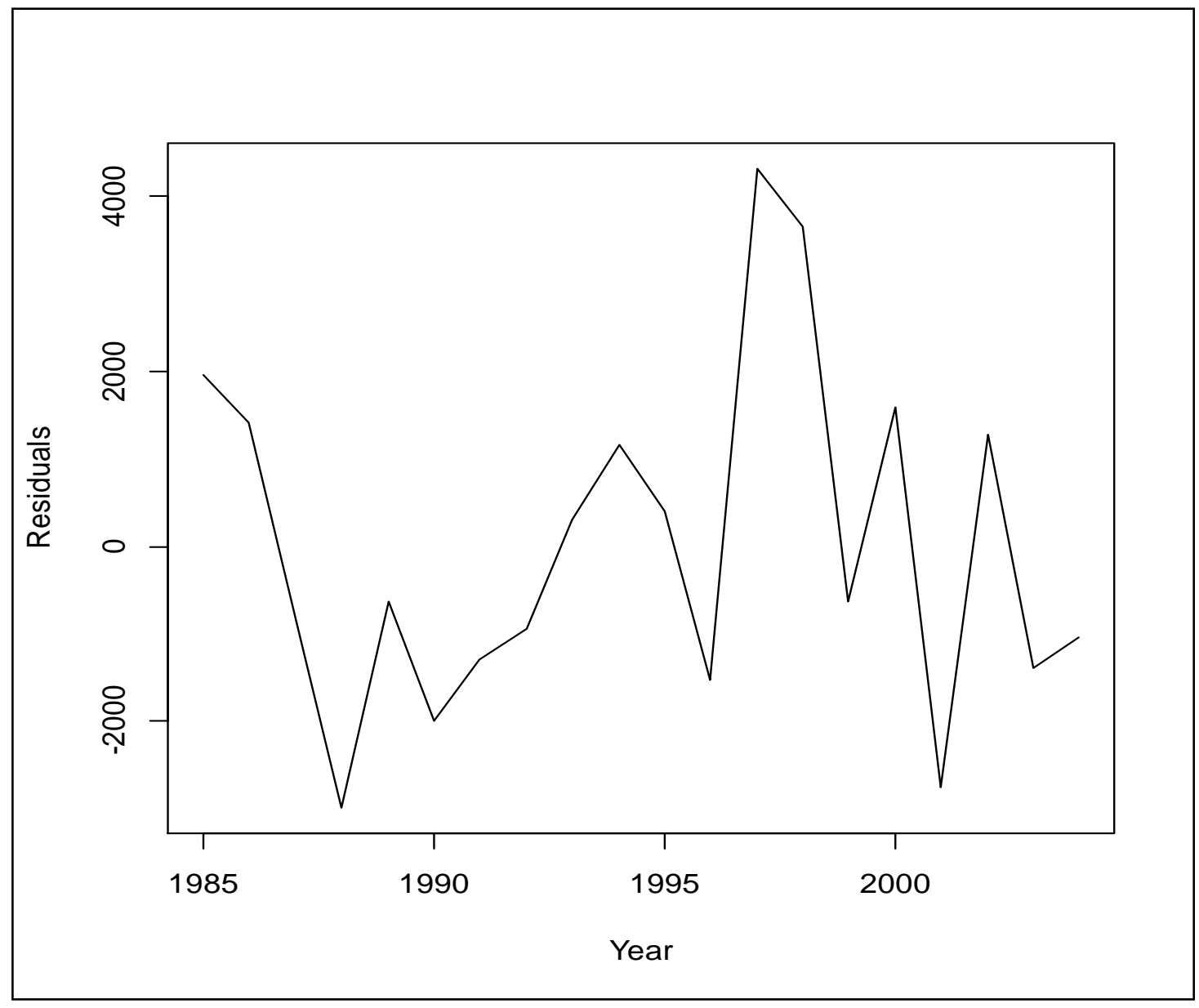

Figure 1. Autocorrelation plots of residuals on annual pricing of black pepper by conducting Multiple Linear Regression with Cochrane Orcutt procedure. 


\section{Plot of Residuals against Transformed of Pricing at Lag 1}

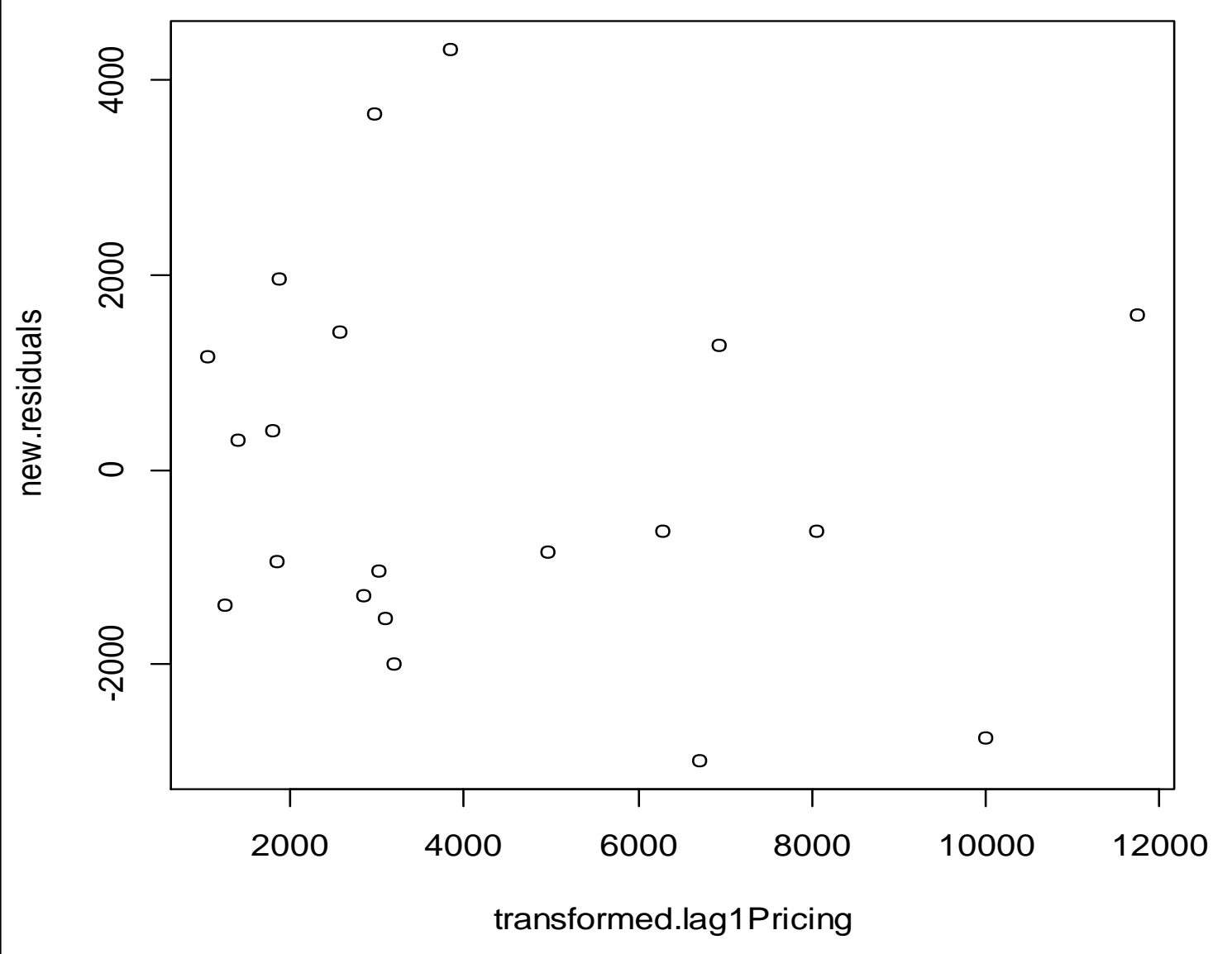

Figure 2. Scatter plot of Residuals against the Transformed of Pricing at lag 1. 


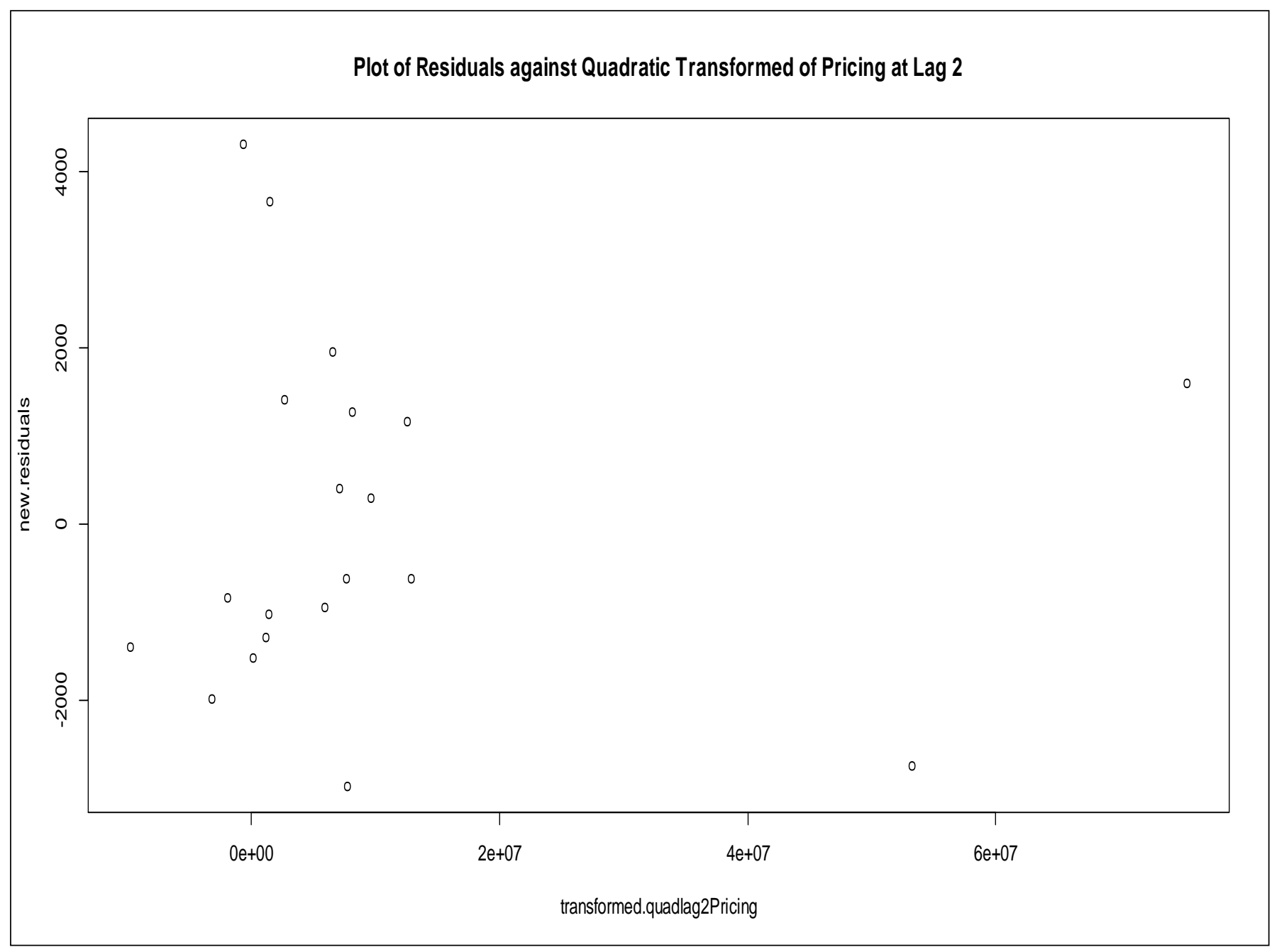

Figure 3. Scatter plot of Residuals against Transformed for Quadratic Term of Pricing at lag 2.

\subsection{Vector Autoregressive Model}

Thus, Hyndman \& Athanasopoulos (2012) had mentioned about asymptotic Portmanteau test to select lag order for VAR model and it should be started at lag order of 1. It is found that VAR(1) model will be formulated to relate the influences on the economy of black pepper. There are four equations altogether to represent each one of the economic variables such as amount of production, total amount of consumption, amount of export and pricing value of black pepper. There is also a constant component, $u_{t}=u_{0}$ to be included in the model as well.

Each equation is extracted from each other causing different significance influences on each one of them. The formulation of the models is based on Tsay (2005) that gives more clearer picture on the relationships among the variables as shown below. 


$$
r_{1 t}=1.0149 r_{1,(t-1)}-1.3323 r_{2,(t-1)}-0.258 r_{3,(t-1)}+0.5467 r_{4(t-1)}+2972 . .9996
$$

Where

$r_{1 t}$ is the amount of production.

$r_{1,(t-1)}$ represents the lag order of 1 for amount of production.

$r_{2,(t-1)}$ is the lag order of 1 for total amount of consumption.

$r_{3,(t-1)}$ resembles the amount of export at lag order of 1.

$r_{4,(t-1)}$ represents the pricing value of black pepper at lag 1.

$$
r_{2 t}=0.0034 r_{1,(t-1)}+1.232 r_{2,(t-1)}-0.0032 r_{3,(t-1)}+0.0006 r_{4(t-1)}-136.8
$$

Where

$r_{2 t}$ is the total amount of consumption.

$$
r_{3 \mathrm{t}}=0.508 r_{1,(t-1)}-0.829 r_{2,(t-1)}-0.0324 r_{3,(t-1)}+0.208 r_{4,(t-1)}+10660
$$

Where

$r_{3 t}$ is the amount of export.

$$
r_{4 t}=-0.5455 r_{1,(t-1)}-0.1693 r_{2,(t-1)}+0.4701 r_{3,(t-1)}+0.6951 r_{4,(t-1)}+3518.3706
$$

Where

$r_{4 t}$ represents the pricing value of black pepper.

Tsay (2005) had suggested identifying the type of relationships among the variables which can be observed from every element that are included in different equation models. However, the main concern is the pricing equation that can be extracted from the VAR (1) model as to be compared with multiple linear regression model in order to identify the underlying structural relationships among the economic variables of black pepper. Hence, there is a directional relationship between Production and Pricing and Export is indirectly related to the 


\section{Macrothink}

Journal of Agricultural Studies

ISSN 2166-0379

2016, Vol. 4, No. 4

Pricing. Thus, there is no relationship between total amount of consumption and the pricing values of black pepper.

From equation 17, it can be interpreted that the mean pricing value of black pepper will decrease by RM 5455 per tonne if the lagged one of amount of production increases by 10000 tonnes. The negative relationship between amount of production and pricing of black pepper can be explained by Halberg et al. (2006) stating that the increasing in the market prices for certain major crop commodities is a result of lowering the amount of production. In this case, Alice \& Peter (2007) had listed the mostly traded plantation commodities around the world as coffee, tea, pepper and natural rubber. As the total amount of consumption at lag 1 increases by 1000 Tonnes, the average of the pricing value will be reduced by RM 169.30 per tonne. As for 10000 tonnes increase in lagged one of amount of export, the mean pricing value of black pepper is increased by RM 4701 per tonne. This theory is also supported by Ravindran (2004) saying that the price of pepper increases as the amount of export increases. The average for the pricing value will increased by RM 695.10 per tonne when the pricing value of black pepper at lag 1 increases by RM 1000 per tonne. Nair (2011) had also stated that the changes in prices of pepper in Thailand are also highly influenced by the previous pricing.

The model is significant since the p-value for F-statistic is less than critical value of 0.05 . Besides that, lagged one of Production, Export and Pricing might have significant influences on the Pricing model. Based on Multiple R-Squared, $80.69 \%$ of variations in pricing value of black pepper can be explained by amount of production, total amount of consumption, amount of export and lagged one of the pricing values. The other $19.31 \%$ can be explained by other factors. By applying the Jarque Bera Test on the residuals, it can be summarised that they are normally distributed. Based on Figure 4.4, few residuals appear to be out of range due to specified reasons similar as the previous explanations on this occurrence. In addition, there is an absence of heteroscedasticity problem for the residuals sine the p-value is not significant. In terms of Durbin Watson test, the value is around 2 which had proven that the error terms are not serially correlated. 


\section{Diagram of fit and residuals for Pricing}

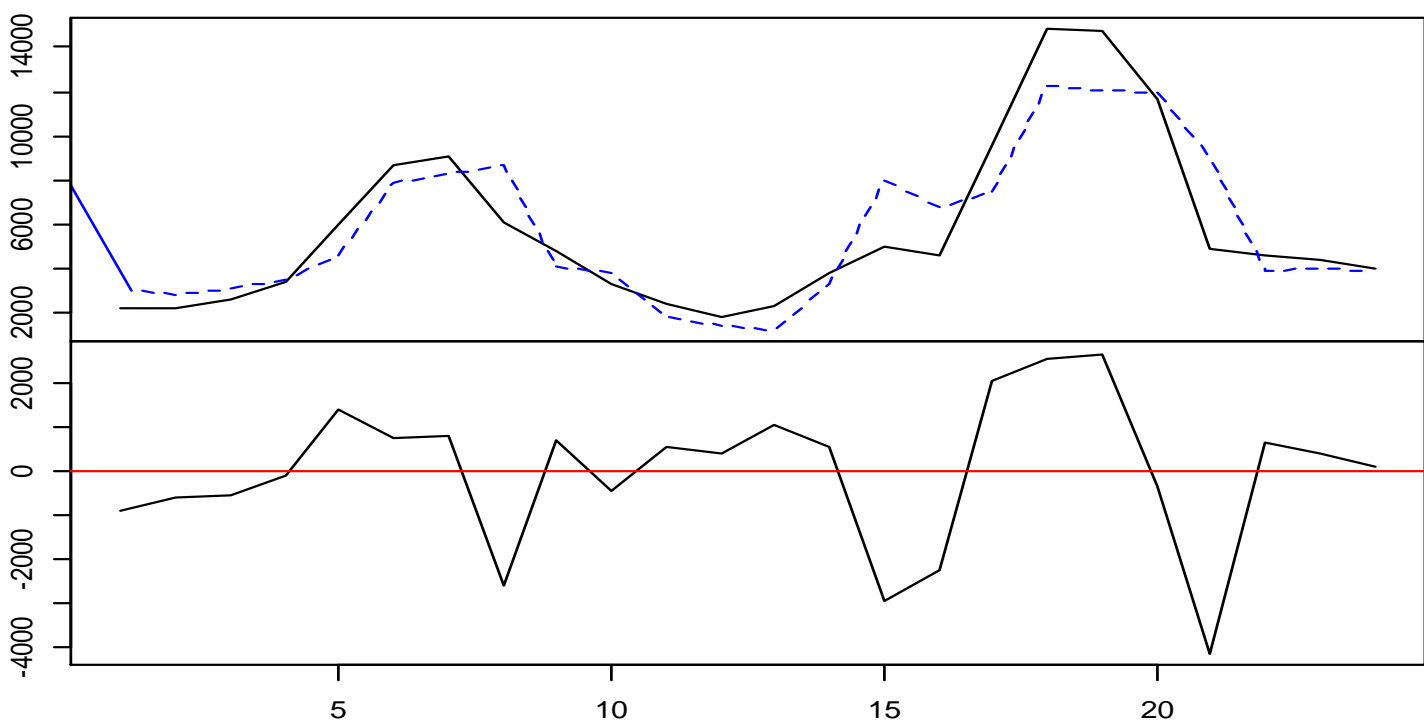

ACF Residuals

PACF Residuals
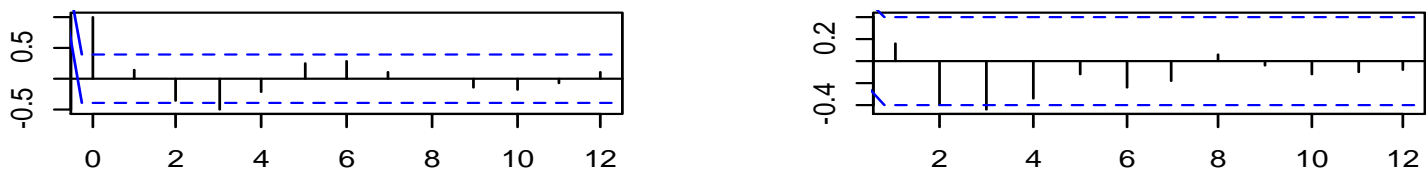

Figure 4. Several plots on the fitted values and residuals of VAR model for annual pricing of black pepper.

\section{Conclusion}

Table 1. Evaluation Summary on Multivariate Models of Pricing Value of Black Pepper

\begin{tabular}{lccc}
\hline \multicolumn{1}{c}{ Model } & MSE & RMSE & MAPE \\
\hline $\begin{array}{l}\text { Multiple Linear } \\
\text { Regression }\end{array}$ & 2915753 & 1707.558 & $11.71 \%$ \\
Vector & 2267417 & 1505.795 & \\
Autoregressive & & & \\
(VAR) model & & \\
\hline
\end{tabular}

From Table 1, it can be summarised that VAR model is more reliable than Multiple Linear Regression since it has a higher Multiple R Square value and it can handle autocorrelation 
problem among the error terms as mentioned by McGuirk \& Spanos (2002). It is also found that the previous year on amount of production, amount of export and the pricing itself are significant factors that influence the annual pricing of black pepper.

\section{References}

Abay, A. (2010). Market Chain Analysis of Red Pepper: The Case of Bure Woreda, West Gojjam Zone Amhara National Regional State, Ethiopia. ( Master's thesis, Haramaya Univeristy).

Alexander, C. (2008). Market Risk Analysis, Quantitative Methods in Finance. John Wiley \& Sons.

Alice, K., \& Peter, K. V. (2007). Commercial Crops Technology: Horticulture Science Series. New India Publishing.

Andersson, S., \& Andersson, M. S. (2013). Package 'het. test'. Retrieved from http://www. http://cran.r-project.org/web/packages/het.test/het.test.pdf.

Brooks, C. (2008). Introductory econometrics for finance. Cambridge university press.

Brooks, C., \& Tsolacos, S. (2010). Real estate modelling and forecasting. Cambridge University Press.

Cowpertwait, P. S., \& Metcalfe, A. V. (2009). Introductory time series with R (pp. 51-55). New York: Springer.

Cramb, R. A. (2007). Land and longhouse: agrarian transformation in the uplands of Sarawak. NIAS Press.

Csáki,C. (2002). Food and Agricultural Policy in Russia: Progress to Date and the Road Forward. World Bank Publications, 23(523), 126.

Dougherty, C. (2011). Introduction to econometrics. Oxford University Press.

Ebeling, P. (2014, April 22). Vietnam's Pepper Exports Expected To Earn US\$1-B In 2014. Live Trading News. Retrieved from http://www. livetradingnews.com.

Halberg, N., Alroe, H. F. \& Krudsen, M. T. (2006). Global development of organic agriculture: Challenges and prospects. Cabi.

Hothorn, T., Zeileis, A., Millo, G., Mitchell, D., \& Zeileis, A. (2009). Package" lmtest": Testing linear regression models. Retrieved from http://www.cran.r-project.org./web/packages/lmtest/ lmtest.pdf.

Hyndman, R. J., \& Athanasopoulos, G. (2012). Forecasting: principles and practice. Retrieved from http://www. otexts.org/fpp.

Kaspersen, L. L., \& Føyn, T. H. Y. (2010). Price Transmission for Agricultural Commodities in Uganda: An empirical vector autoregressive analysis. International Food Policy Research Institute (IFPRI). 


\section{Macrothink}

Journal of Agricultural Studies

ISSN 2166-0379

2016, Vol. 4, No. 4

Kishore, N., \& Alimuhammad, L. (2008). Pepper Quarterly- Brazilian Pepper Board. Anandrathi Commodity Research Pepper.

Kutner, M. H., Nachtsheim, C., \& Neter, J. (2008). Applied linear regression models. McGraw-Hill/Irwin.

Lau, E., Puah, C. H., Oh, S. L., \& Lo, Y. C. (2008). Causality between White Pepper and Black Pepper: Evidence from Six Markets in Sarawak.

Le Boudec, J. Y. (2010). Performance evaluation of computer and communication systems. EPFL Press.

Luetkepohl, H. (2011). Vector Autoregressive Models. Economics Working Papers ECO2011/30, European University Institute.

Luo, F. (2011). Influence of the External Shocks on Price Fluctuations of Agricultural Products of China: An Empirical Analysis Based on the VAR Model. In Applied Economics, Business and Development, 374-381.

Ravindran, P. N. (Ed.). (2004). Black pepper: Piper nigrum. CRC Press.

Redclift, M. (Ed.). (2002). Sustainability: Life chances and livelihoods. Routledge.

Samprit Chatterjee, \& Ali S. Hadi (2013). Regression analysis by example. John Wiley \& Sons.

Stock, J. H., \& Watson, M. W. (2001). Vector autoregressions. Journal of Economic perspectives, 101-115.

Tsay, R. S. (2005). Analysis of financial time series. John Wiley \& Sons.

Udegbe, S. E., Udegbe, M. I., Abayomi, O. T., \& RA, H. (2012) Marketing of Pepper in the Metropolitan Region of Lagos State, Nigeria. Australian Journal of Business and Management Research Vol, 2(01), 27-36.

Vivek Ajmani (2011). Applied econometrics using the SAS system. John Wiley \& Sons.

Wooldridge, J. (2012). Introductory econometrics: A modern approach. Cengage Learning.

\section{Copyright Disclaimer}

Copyright for this article is retained by the author(s), with first publication rights granted to the journal.

This is an open-access article distributed under the terms and conditions of the Creative Commons Attribution license (http://creativecommons.org/licenses/by/3.0/). 